\title{
Production Decision Optimization for Iron and Steel Scrap Remanufacturing considering Carbon Emission and Delivery Time
}

\author{
Changping Liu $\mathbb{D}^{1,2}$ and Weiyu Zhou ${ }^{3}{ }^{3}$ \\ ${ }^{1}$ Faculty of Management Engineering, Huaiyin Institute of Technology, Huaian 223200, China \\ ${ }^{2}$ Jiangsu Smart Factory Engineering Research Center, Huaian 223003, China \\ ${ }^{3}$ Faculty of Business, Huaiyin Institute of Technology, Huaian 223001, China
}

Correspondence should be addressed to Changping Liu; lcpzwy@hyit.edu.cn

Received 30 March 2021; Accepted 3 May 2021; Published 12 May 2021

Academic Editor: Huihua Chen

Copyright () 2021 Changping Liu and Weiyu Zhou. This is an open access article distributed under the Creative Commons Attribution License, which permits unrestricted use, distribution, and reproduction in any medium, provided the original work is properly cited.

\begin{abstract}
Under the requirements of the national carbon reduction target, the recycling and remanufacturing of scrap iron and steel are taken by major iron and steel enterprises as requirements for implementing industrial carbon emission reduction and are incorporated into their production strategies. The scheduling optimization of scrap iron and steel remanufacturing processes plays an important role in the energy saving and emission reduction of iron and steel enterprises. In this paper, a remanufacturing production decision model for scrap iron and steel considering both the product delivery time and carbon emissions was established, and a discrete krill swarm algorithm was designed to solve the multiobjective production decision model. The effectiveness of the model and the algorithm was verified by an example, demonstrating a good decision-making reference for the implementation of energy conservation and emission reduction in iron and steel enterprises.
\end{abstract}

\section{Introduction}

In traditional production decision-making, only economic indicators related to cost, profit, or quality are considered, and energy consumption indicators related to the environment are seldom considered. Under the constraints of the Kyoto Protocol, countries or regions must decompose their emission reduction targets from the macro level to the micro level of production and operation. As a key industry of energy conservation and emission reduction, the iron and steel industry plays an important role in the national carbon reduction target. The recycling and remanufacturing of scrap iron and steel are included in the production strategies of major iron and steel enterprises as a requirement for implementing industrial carbon emission reduction.

At present, many scholars have studied the production decision optimization of remanufacturing enterprises under the influence of carbon emission reduction and have achieved some promising results. Generally speaking, these research results mainly focused on two aspects, the first of which was supply chain management under the consideration of carbon emissions. For example, Amar et al. proposed a carbon market-sensitive strategic planning model for sustainable supply chains [1]. Paksoy et al. studied closed-loop supply chains based on economic and environmental indicators [2]. Benjaafar et al. incorporated carbon emissions into the supply chain system and established an operation decision-making model for a single enterprise under various scenarios, such as a mandatory carbon emission quota and carbon tax and carbon quota trading [3]. Zakeri et al. studied the impact of carbon trading and carbon tax policies on enterprise management performance in a supply chain [4].

The second aspect concerned the production decisions of manufacturing/remanufacturing enterprises considering carbon emissions. For example, Letmathe and Balakrishnan 
constructed the optimal linear model and mixed integer programming model and considered different environmental constraints and production constraints to determine the optimal product portfolio and production quantity. These models can help enterprises analyze the impact of carbon emission quota, carbon tax, and carbon trading cost on their production decisions [5]. Ferrer and Swaminathan studied the two-cycle and multicycle remanufacturing production and pricing problems under oligopoly and duopoly [6]. Du et al. studied the impact of the emission quota and trading mechanisms on the optimal production and operation of enterprises in a deterministic demand market [7]. Chang et al. analyzed the similarities and differences in enterprises' remanufacturing technology selection behavior and production decisions under different scenarios, such as no carbon emission constraints and carbon quota, carbon tax, carbon subsidy, and carbon rights trading [8-10]. Chen and Xiong studied the manufacturing/remanufacturing decision-making problem under the mandatory emission reduction and carbon rights trading policies and compared the differences of manufacturers' optimal decision-making under the two kinds of emission reduction policies [11]. In addition, Ren et al., Zhang et al., and $\mathrm{Xu}$ et al. studied the impact of carbon emissions on remanufacturing production decisions from different perspectives [12-14].

The current research on the production decision-making of remanufacturing enterprises in the context of carbon reduction is mostly carried out at the macro level, and the research perspective is mainly focused on the impact of various carbon reduction factors on enterprises and their corresponding production decision-making. The research at the micro level, especially on specific industries, is relatively lacking. Based on the remanufacturing process for scrap iron and steel, this paper discusses the multiobjective production decision optimization of remanufacturing enterprises considering carbon emissions from the production operation level, and a discrete krill herd optimization algorithm was designed to solve it. The effectiveness of the algorithm was verified by an example, which can provide a reference for the production decision-making of remanufacturing enterprises in the iron and steel manufacturing industry.

\section{Description of the Problem and Hypothesis}

The remanufacturing of scrap iron and steel is a process in which recycled scrap steel is smelted as raw material to produce steel products, including two stages of reprocessing and remelting [15]. In the reprocessing stage, scrap steel remanufacturing enterprises adopt different treatment methods such as shearing, crushing, sorting, cleaning, and preheating to remove the nonferrous metal and nonmetallic impurities in various scrap steel as far as possible, so as to make the recycled scrap iron and steel into a qualified furnace burden for easy loading and transportation and suitable for steelmaking. The remelting stage is used to smelt the scrap steel processed in the reprocessing stage to produce steel products, which mainly includes steelmaking, continuous casting, cold rolling, hot rolling, rough rolling, finishing rolling, pickling, final finishing, annealing, and other processes. The whole process has a long cycle and different process properties.

In this paper, it was assumed that the main goal of scrap steel remanufacturing enterprises is to shorten the product delivery time, so as to respond to market changes in a timely manner, to meet customer needs, and to improve customer satisfaction. Second, while meeting the first goal, enterprises hope that the carbon emissions in the production process will be as small as possible. According to the above objectives, the corresponding multiobjective production decisionmaking model was established. The first decision objective is represented by the minimum makespan of each batch of scrap steel from reprocessing to remelting. For simplicity, it does not consider the time consumption of the other links in the process from the production line to the final delivery. The second decision objective is represented by the minimum carbon emissions in the remanufacturing process of scrap iron and steel. The two decision-making objectives are equally important to scrap remanufacturing enterprises.

The carbon emissions of the scrap iron and steel remanufacturing production process are mainly composed of three parts:

(1) The carbon emissions of equipment processing workpiece

(2) The carbon emission of equipment idling

(3) The carbon emission of workpiece waiting for processing [16]

Among them, the first part of the carbon emissions, because of the time of machining each workpiece, is determined, so the total carbon emissions generated by machining the same batch of workpieces are the same. Constrained by the process flow of iron and steel processing, the different production decisions have different effects on the carbon emissions of the second and third parts. Experience shows that, in the manufacturing industry, the energy consumed when the equipment is idling accounts for a large proportion of the total energy consumption. Therefore, in the process of scrap steel processing, the equipment should be idling as little as possible. In particular, when the equipment is fully utilized, i.e., the machine is not idling, the carbon emissions of the second part is zero. For the same reason, the less the workpiece has to wait for the equipment to process, the better. When the workpiece does not stay or wait in the machine for the whole processing, that is, when the workpiece is not waiting, the carbon emissions of the third part are zero. Therefore, the second decision-making goal only needs to minimize the carbon emissions of the second and third parts. In the process of steel production, the carbon emissions of the second part are usually much higher than those of the third part.

The above two decision-making objectives are contradictory. In order to achieve the first objective, in the whole process of scrap iron and steel processing, each workpiece process should be connected as much as possible, and the waiting time of the workpiece should be as short as possible. Constrained by steel processing technology, this will 
increase the idling time of the machine, which will increase the carbon emissions accordingly. In the same way, in order to achieve the second goal, the machine should idle as little as possible. Due to the process constraints, the waiting time of the workpiece will be increased, which will prolong the completion time and affect the delivery time.

\section{Multiobjective Production Decision Model for Scrap Iron and Steel Remanufacturing}

According to the above description and assumption, we established the production decision model of scrap iron and steel remanufacturing with two decision objectives, as shown in the following:

$$
\left\{\begin{array}{l}
\min f_{1}=C_{\max }^{1}(\pi), \\
\min f_{2}=\eta \cdot\left\{C_{\max }^{2}(\omega)\right\},
\end{array}\right.
$$

subject to the following conditions:

(1) The machine uniqueness constraint means that each machine can only process one workpiece at the same time

(2) The uniqueness constraint of the workpiece means that a workpiece cannot be processed on different machines at the same time

(3) The machining process satisfies the nuninterruptible constraint

(4) The processing sequence of workpieces on each machine is the same and the time is determined

(5) The order of each workpiece machined is the same

In the model, the decision objective $f_{1}$ is the shortest expected delivery time, the decision objective $f_{2}$ is the least expected carbon emission, and $\eta$ is the carbon dioxide emission coefficient. For the iron and steel manufacturing industry, it usually takes $264 \mathrm{~kg} / \mathrm{kWh}$, and (1) (5) are the constraints of the scrap iron and steel remanufacturing process.

Without losing generality, it is assumed that each workpiece is processed in the order of machine $1 \sim \mathrm{m}$, and the delivery time $C_{\max }^{1}(\pi)$ in target (1) is calculated according to equations (2) and (3):

$$
\begin{aligned}
& C\left(j_{1}, k\right)=\sum_{r=1}^{k} t_{j_{1}, r}, \quad k=1, \ldots, m \\
& C\left(j_{i}, k\right)=C\left(j_{i-1}, 1\right)+\sum_{r=1}^{k} t_{j_{i}, r}+\Delta\left(j_{i}\right), \\
& \quad i=2, \ldots, n ; k=1, \ldots, m \\
& \left.\begin{array}{c}
\Delta\left(j_{i}\right)=\max \left\{\max _{2 \leq k \leq m}\left[C\left(j_{i-1}, k\right)-C\left(j_{i-1}, 1\right)-\sum_{r=1}^{k-1} t_{j_{i}, r}\right], 0\right.
\end{array}\right\}
\end{aligned}
$$

$C_{\max }^{1}(\pi)=C\left(j_{n}, m\right)$
In the above equations, $\left\{j_{i} \mid i=1, \ldots, n\right\}$ represents the set of jobs, $\left\{k_{l} \mid l=1, \ldots, m\right\}$ represents the set of machines, $t_{j_{i}, k}$ represents the processing time of job $j_{i}$ on machine $k$, and $C\left(j_{i}, k\right)$ represents the completion time of job $j_{i}$ on machine $k$.

Equation (2) shows the completion time of workpiece $j_{1}$ on machine $k$; (3) shows the completion time of workpiece $j_{i}(i>1)$ on machine $k$; (4) shows the waiting time of workpiece $j_{i}$ due to the limited buffer between machines; in (5), $C_{\max }^{1}(\pi)$ is the completion time of processing $n$ workpieces. We can see that (2)-(5) are a group of recursive equations.

Similarly, assuming that each workpiece is processed in the order of machine $1 \sim \mathrm{m}$, the completion time $C_{\max }^{2}(\omega)$ of the minimum carbon emission production decision in goal (2) is calculated according to equations (6) and (7):

$$
\begin{gathered}
C_{\max }^{2}(\omega)=C_{j_{n}, m}=\sum_{k=2}^{m} f_{k-1, k}\left(j_{n}\right)+\sum_{i=1}^{n} t_{j_{i}, 1}, \\
\Delta_{k-1, k}\left(j_{i}\right)=t_{j_{i}, k}+\max \left\{0, \Delta_{k-1, k}\left(j_{i-1}\right)-t_{j_{i}, k-1}\right\}, \\
i=2,3, \ldots, n ; k=2,3, \ldots, m .
\end{gathered}
$$

Equations (6) and (7) are recursive equations for calculating $C_{\max }^{2}(\omega) \cdot t_{j_{i}, k}$ represents the processing time of workpiece $j_{i}$ on machine $k$, and $C\left(j_{i}, k\right)$ represents the completion time of workpiece $j_{i}$ on machine $k . \Delta_{k-1, k}\left(j_{i}\right)$ denotes the completion time difference of workpiece $j_{i}$ on adjacent machines $k-1$ and $k(k=2,3, \ldots, m)$. In particular, there is $\Delta_{1,2}\left(j_{1}\right)=t_{j_{1}, 2}$. The meanings of the other symbols are the same as above.

\section{Multiobjective Production Decision Optimization of Scrap Iron and Steel Remanufacturing Based on the Discrete Krill Herd Algorithm}

For multiobjective decision-making problems, there is usually no absolute optimal solution to ensure multiple objectives reach the optimal at the same time, so we need adopt different methods according to the characteristics of specific problems. The remanufacturing process of scrap iron and steel belongs to the flow shop production mode. In the two objective decision-making models of scrap iron and steel remanufacturing established by (1), the first decision-making objective is similar to the no-wait flow shop-scheduling model; the second decision-making objective is similar to the no-idle flow shop-scheduling model. It has been proven that the no-wait and no-idle flow shop-scheduling problems with three machines or more are nondeterministic problems with polynomial complexity. At present, there is no global optimization algorithm with polynomial computational complexity $[17,18]$. In this paper, we designed a discrete krill herd optimization algorithm to solve the problem. The test results show that the designed algorithm is effective. 
4.1. Discrete krill Herd Optimization Algorithm for the Multiobjective Production Decision of Scrap Steel Remanufacturing. The traditional krill herd optimization algorithm was proposed by Gandomi et al. [19], which is mainly used in the field of function optimization [20-23], and the application of combinatorial optimization is rare. In traditional krill herd algorithm, the individual position is encoded by a continuous value vector, and the position update operation is completed in continuous space. The multiobjective production decision-making problem is a combinatorial optimization problem, which needs to design the corresponding coding and location update methods according to the discrete nature of the problem. Based on the mechanism of the krill herd optimization algorithm, we designed a discrete krill swarm optimization algorithm to solve the multiobjective production decision-making problem.

4.1.1. Individual Coding Mode. In the discrete krill herd algorithm, krill individuals are directly represented by integer coding based on an operation sequence, and the position vector $\left\{X_{i} \mid i=1, \ldots, n\right\}$ of krill individual $i$ represents a sort of processing sequence of workpiece $\left\{\pi_{j} \mid j=1, \ldots, m\right\}$ to establish mapping between the individual position and the processing sequence. This coding method is simple and feasible, and all of the solutions are feasible. For example, if the individual position vector is $X_{i}=[5,4,1,3,8,7,6,2]$, the processing sequence mapped to the workpiece is $\pi_{j}=\left\{j_{5}, j_{4}, j_{1}, j_{3}, j_{8}, j_{7}, j_{6}, j_{2}\right\}$, so that the fitness of the scheduling solution corresponding to the individual position of krill can be calculated.

4.1.2. Calculation Method of the Individual Distance. In the krill herd optimization algorithm of the function optimization problem, the distance between individuals is calculated by the Euclidean space distance, which is not suitable for the discrete krill herd optimization algorithm. According to the characteristics of the problem to be optimized, in the discrete krill herd optimization algorithm, the individual position vector is represented by the workpiece processing sequence, and different position vectors represent different processing sequences. Therefore, in the discrete krill herd optimization algorithm, the "individual distance" is represented by the degree of difference in the job processing and sequencing, which is defined as per the following equation:

$$
r_{i j}=\frac{\sum_{s=1}^{n}\left|x_{j, s}-x_{i, s}\right|}{R} .
$$

In (8), $x_{i, s}$ and $x_{j, s}$ represent the s-th dimension codes of krill individual $i$ and krill individual $j, n$ represents the number of workpieces, and $R$ is the upper limit of the molecular term value, which is calculated according to the following equation:

$$
R= \begin{cases}\frac{n^{2}}{2}, & n \in \text { even number, } \\ \frac{\left(n^{2}-1\right)}{2}, & n \in \text { odd number }\end{cases}
$$

where we can infer that $r_{i j} \in[0,1]$. The size of the "individual distance" reflects the degree of difference in the processing order. The farther the "distance," the greater the difference between individuals.

4.1.3. Location Update Strategy. Krill individual location updating is the core of the krill herd optimization algorithm. Affected by the three parts of virtual food location, individuals in the neighborhood, and random diffusion motion, the discrete krill herd optimization algorithm was designed for these three parts.

\section{The Impact of Virtual Food}

The average fitness of the krill population is defined as virtual food, and the position is updated by comparing individual fitness with virtual food. The update strategy is shown in the following equation:

$$
x_{i}^{t+1}= \begin{cases}\operatorname{LOX}\left(x_{i}^{t} \otimes x_{\text {food }}^{t}\right), & \text { if } f(i) \prec f(\text { food }), \\ \operatorname{PMX}\left(x_{i}^{t} \otimes x^{\text {gbest }}\right), & \text { elseif } f(i) \succ f(\text { food }), \\ \operatorname{MU}\left(x_{i}^{t}\right), & \text { else, }\end{cases}
$$

where $f(i)$ and $f$ (food) refer to the fitness of the krill individuals and virtual food, respectively, and $t$ is the current search time. In the process of $t+1$ search, we compared the fitness of the $\mathrm{i}$-th individual and virtual food. If $f(i) \prec f$ (food), the individual positions $x_{i}^{t}$ and $x_{\text {food }}^{t}$ are crossed in a linear order to form a new individual position, $x_{i}^{t+1}$; otherwise, the individual position $x_{i}^{t}$ and the optimal individual $x^{\text {gbest }}$ of the current population are crossed in partial mapping to form a new position, $x_{i}^{t+1}$. If the above conditions are not met, the current individual position $x_{i}^{t}$ is mutated to produce a new position, $x_{i}^{t+1}$. Among them, the linear order crossover operation can keep the relative position of the process between individuals and the absolute position of the front end of the process as far as possible, and the partial mapping crossover operation can satisfy the pattern theorem to a certain extent, so that the best pattern can be retained as much as possible.

5.1. The Influence of Neighborhood Groups on Individuals. According to the definition of the distance between krill individuals in (8), the neighborhood range can be determined, and the position is updated by comparing with the fitness of individuals in the neighborhood. The update strategy is shown in the following equation:

$$
x_{i}^{t+1}=\left\{\begin{array}{cc}
x_{i}^{t} \otimes x_{j \in \mathrm{ngb}}^{t}, & \text { if } f\left(x_{i}^{t} \otimes x_{j \in \mathrm{ngb}}^{t}\right)>f\left(x_{i}^{t}\right), \\
x_{i}^{t}, & \text { else, }
\end{array}\right\}
$$

where ngb represents the neighborhood range and $x_{j}^{t}$ represents the spatial position of the $j$-th krill individual within the neighborhood range in the $t$-th search.

The updating process is as follows: in the $t+1$ round search process, the neighborhood range is determined according to the distance between krill individuals, and 
Table 1: Processing time matrix.

\begin{tabular}{|c|c|c|c|c|c|c|c|c|c|c|}
\hline \multirow{2}{*}{ Jobs } & \multicolumn{10}{|c|}{ Procedure } \\
\hline & 1 & 2 & 3 & 4 & 5 & 6 & 7 & 8 & 9 & 10 \\
\hline 1 & 28 & 18 & 38 & 11 & 97 & 23 & 90 & 52 & 79 & 63 \\
\hline 2 & 50 & 30 & 75 & 82 & 38 & 39 & 28 & 84 & 48 & 57 \\
\hline 3 & 75 & 50 & 33 & 58 & 56 & 41 & 51 & 29 & 75 & 97 \\
\hline 4 & 65 & 42 & 66 & 29 & 36 & 29 & 10 & 84 & 14 & 67 \\
\hline 5 & 84 & 68 & 42 & 41 & 86 & 23 & 95 & 30 & 73 & 97 \\
\hline 6 & 33 & 72 & 79 & 85 & 81 & 51 & 72 & 19 & 48 & 48 \\
\hline 7 & 91 & 66 & 87 & 88 & 97 & 36 & 21 & 59 & 61 & 4 \\
\hline 8 & 51 & 23 & 100 & 93 & 48 & 84 & 74 & 7 & 98 & 55 \\
\hline 9 & 58 & 61 & 17 & 54 & 25 & 71 & 52 & 47 & 49 & 86 \\
\hline 10 & 44 & 27 & 40 & 19 & 34 & 33 & 3 & 89 & 39 & 66 \\
\hline 11 & 70 & 94 & 7 & 19 & 31 & 48 & 38 & 48 & 73 & 34 \\
\hline 12 & 60 & 38 & 34 & 55 & 63 & 28 & 70 & 35 & 68 & 88 \\
\hline 13 & 39 & 33 & 53 & 87 & 2 & 6 & 51 & 42 & 93 & 67 \\
\hline 14 & 72 & 35 & 45 & 20 & 84 & 23 & 10 & 34 & 8 & 48 \\
\hline 15 & 100 & 71 & 80 & 89 & 47 & 15 & 90 & 33 & 97 & 26 \\
\hline 16 & 79 & 23 & 57 & 54 & 70 & 99 & 85 & 5 & 9 & 4 \\
\hline 17 & 14 & 23 & 36 & 79 & 4 & 65 & 78 & 51 & 95 & 79 \\
\hline 18 & 3 & 32 & 81 & 26 & 19 & 59 & 80 & 90 & 44 & 33 \\
\hline 19 & 68 & 33 & 94 & 37 & 33 & 74 & 64 & 50 & 22 & 17 \\
\hline 20 & 94 & 17 & 54 & 27 & 55 & 34 & 7 & 56 & 10 & 41 \\
\hline
\end{tabular}

TABle 2: Multiobjective decision-making scheme.

\begin{tabular}{lcccc}
\hline Scheme & Corresponding processing sequence & Delivery time (minutes) & Carbon emissions (ton) \\
\hline 1 & 1013114912318168671551712191420 & 2042 & 2106 \\
2 & 1013114912171258671519318161420 & 2043 & 2050 \\
3 & 1013114912171219318586715161420 & 2046 & 2015 \\
4 & 1020141311491221931711858671516 & 2050 & 1981 \\
5 & 1013114121711893219586715161420 & 2071 & 1968 \\
6 & 1012193131149121718586715161420 & 2082 & 1954 \\
7 & 1017121914201311491231858671516 & 21090 & 1930 \\
8 & 1013181712193114912586715161420 & 2107 & 1918 \\
9 & 1017191221931142014131858671516 & 2126 & 1913 \\
10 & 1012193161413114912171858671520 & 1892 \\
\hline
\end{tabular}

individuals in the neighborhood are selected. Individual $x_{i}^{t}$ crosses with the selected individual $x_{j}^{t}$ in the neighborhood, and the optimal individual is selected as the new individual, $x_{i}^{t+1}$; if there are no krill individuals in the neighborhood, individual $x_{i}^{t}$ crosses with the optimal $x^{\text {gbest }}$ to form a new individual.

5.2. The Influence of Random Diffusion Motion. After each optimization, a certain proportion of individuals with poor performance are selected for reinitialization to increase the diversity of the population and to maintain the continuous evolution ability of the population.

In this way, the position updating formula of the discrete krill herd optimization algorithm can be expressed by the following equation:

$$
\mathbf{x}_{i}^{t+1}=F\left(\mathbf{x}_{i}^{t}\right) \oplus N\left(\mathbf{x}_{i}^{t}\right) \oplus D\left(\mathbf{x}_{i}^{t}\right) .
$$

In the formula (12), $F\left(\mathbf{x}_{i}^{t}\right)$ represents the influence of virtual food, $N\left(\mathbf{x}_{i}^{t}\right)$ represents the influence of neighborhood groups, and $D\left(\mathbf{x}_{i}^{t}\right)$ represents the influence of individual random diffusion motion. The individual position updating of krill is completed by the comprehensive influence of these three aspects.

The time complexity of the discrete krill swarm algorithm in this paper is $O\left(C \cdot \operatorname{Max} T \cdot m^{2}\right)$, where $C$ is a constant, MaxT is the maximum number of iterations, and $m$ is the number of krill swarm individuals.

5.3. Simulation Experiment and Analysis. Aiming at the established multiobjective production decision-making model of scrap iron and steel remanufacturing, the effectiveness of the model and algorithm was verified by simulation experiments. Assuming that there are 20 batches of scrap iron and steel waiting to be processed, each batch of scrap iron and steel needs ten processing procedures, and the processing procedure needs to meet the constraints of steel manufacturing process. The processing time of each batch of scrap iron and steel waiting to be processed in each process is shown in Table 1, and the time unit is minutes.

The parameters of the multiobjective discrete krill herd optimization algorithm were set as follows: the number of 


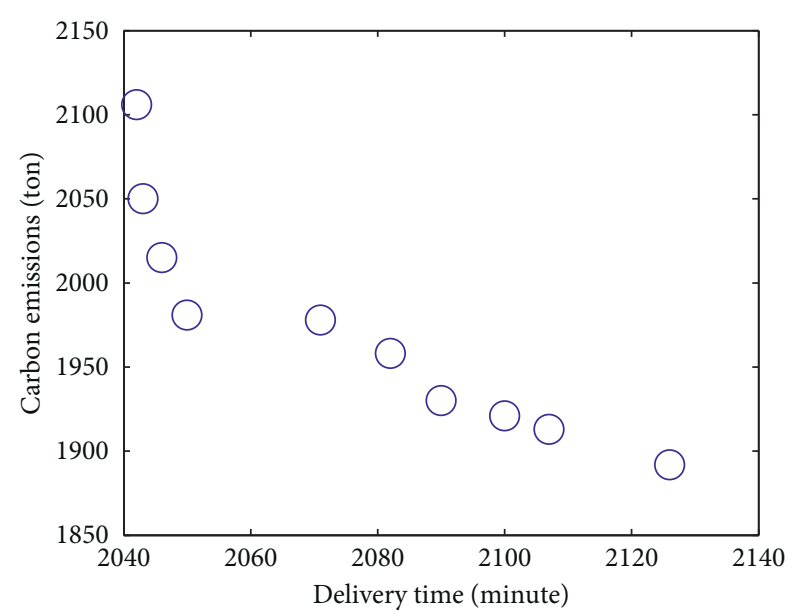

Figure 1: Pareto solution of the multiobjective remanufacturing production decision.

krill swarm, $m=30$; the proportion of cross individuals in the neighborhood, $40 \%$; the proportion of reinitialized individuals, 5\%; the maximum number of searches, $\operatorname{MaxT}=50$; independent runs for the algorithm, 20 times. The optimization scheme obtained is shown in Table 2.

According to the simulation results, we can see that different production decisions have different effects on the delivery date and carbon emissions. Under the constraints of the steel manufacturing process, there is a certain negative correlation between completion time and carbon emissions. The ten production decision schemes listed in Table 2 are partial Pareto solutions found by the algorithm, as shown in Figure 1.

\section{Conclusions}

Remanufacturing is not only an effective method for achieving sustainable development, but also one of the most important ways for manufacturing enterprises to implement low-carbon transformation. The mode of remanufacturing is conducive to achieving the comprehensive goals of environmental protection and sustainable economic development.

Taking the remanufacturing of scrap iron and steel as an example, this paper established a multiobjective production decision-making model considering both carbon emissions and delivery time and designed a discrete krill swarm optimization algorithm to solve the model. The effectiveness of the algorithm was verified by an example. The multiple optimization schemes obtained by the intelligent optimization algorithm were a Pareto solution set, which were equivalent in theory. However, in reality, remanufacturing enterprises can only choose one optimization scheme to implement. According to the actual market situation, enterprises can assign different weights to different objectives and can choose an optimization scheme, so as to provide a reference for remanufacturing enterprises' production decision-making.

\section{Data Availability}

The data used to support the findings of this study are included within the article.

\section{Conflicts of Interest}

The authors declare no conflicts of interest.

\section{Authors' Contributions}

In this article, C. Liu and W. Zhou designed the study. C. Liu wrote the first draft and also programmed the discrete krill herd algorithm to solve the multiobjective production decision model in this paper. W. Zhou implemented all experiments and performed the design of figures. All authors contributed to the manuscript revision and read and approved the submitted version.

\section{Acknowledgments}

This research was funded by The National Social Science Foundation of China, Grant no. 17BSH040, and the MOE (Ministry of Education in China) Project of Humanities and Social Sciences, Grant no. 16YJA630032.

\section{References}

[1] R. Amar, C. Amin, and P. Marc, "Carbon market sensitive sustainable supply chain network design," International Journal of Management Science and Engineering, vol. 5, pp. 30-38, 2010.

[2] T. Paksoy, T. Bektaş, and E. Özceylan, "Operational and environmental performance measures in a multi-product closed-loop supply chain," Transportation Research Part E: Logistics and Transportation Review, vol. 47, no. 4, pp. 532546, 2011.

[3] S. Benjaafar, Y. Li, and M. Daskin, "Carbon footprint and the management of supply chains: insights from simple models," IEEE Transactions on Automation Science and Engineering, vol. 10, no. 1, pp. 99-116, 2013.

[4] A. Zakeri, F. Dehghanian, B. Fahimnia, and J. Sarkis, "Carbon pricing versus emissions trading: a supply chain planning perspective," International Journal of Production Economics, vol. 164, pp. 197-205, 2015.

[5] P. Letmathe and N. Balakrishnan, "Environmental considerations on the optimal product mix," European Journal of Operational Research, vol. 167, no. 2, pp. 398-412, 2005.

[6] G. Ferrer and J. M. Swaminathan, "Managing new and remanufactured products," Management Science, vol. 52, no. 1, pp. 15-26, 2006.

[7] S. F. Du, J. F. Dong, and L. Liang, "Optimal production policy with emission permits and trading," Chinese Journal of Management Science, vol. 17, pp. 81-86, 2009, in Chinese.

[8] X. Y. Chang and H. Y. Zhu, "Reasearch on production decision of manufacturing/remanufacturing under the constraint of carbon emission," Sci. Tech. Prog. Poli.vol. 29, pp. 75-78, 2012, in Chinese.

[9] X. Y. Chang, Y. X. Wang, and H. Y. Zhu, "Optimal production decision for manufacturing/remanufacturing with constraint of carbon emission," Systems Engineering, vol. 32, pp. 49-56, 2014, in Chinese.

[10] X. Chang, H. Xia, H. Zhu, T. Fan, and H. Zhao, "Production decisions in a hybrid manufacturing-remanufacturing system with carbon cap and trade mechanism," International Journal of Production Economics, vol. 162, pp. 160-173, 2015.

[11] C. R. Chen and Z. K. Xiong, "Production decisions of the carbon manufacturer remanufacturing under emission 
constraint," Journal of Systems Science and Systems Engineering, vol. 29, pp. 537-549, 2014, in Chinese.

[12] J. Ren, P. He, and B. G. Gong, "The decision of production and carbon trading under capacity constraints and cap-and-trade mechanism," Systems Engineering, vol. 34, pp. 47-52, 2016, in Chinese.

[13] H. Y. Zhang, Y. H. Li, and Y. X. Hang, "Research on remanufacturing strategy of enterprises under carbon capand-trade mechanism," Soft Science, vol. 32, pp. 87-91, 2018, in Chinese.

[14] M. L. Xu, H. Yin, and H. Y. Jian, "Manufacturing/remanufacturing decision considering WTP differentiation and risk averse remanufacturer: based on different patent protection models carbon cap-and-trade mechanism," Science Technology and Management Research, vol. 38, pp. 216-222, 2018.

[15] L. Wei, W. D. Chen, and Y. Yang, "Decision-makings on the scrap iron and steel remanufacturing considering the introduction of carbon emission reduction investment," Industrial Engineering and Management, vol. 23, pp. 65-71, 2018, in Chinese.

[16] W. D. Chen and S. D. Cui, "Multi-objective scheduling dimensional reduction model and algorithm for iron and steel scrap remanufacturing with carbon emissions considered," Systems Engineering, vol. 33, pp. 101-108, 2015, in Chinese.

[17] M. R. Garey, D. S. Johnson, and R. Sethi, "The complexity of flowshop and jobshop scheduling," Mathematics of Operations Research, vol. 1, no. 2, pp. 117-129, 1976.

[18] H. Röck, "The three-machine no-wait flow shop is np-complete," Journal of the ACM, vol. 31, no. 2, pp. 336-345, 1984.

[19] A. H. Gandomi and A. H. Alavi, "Krill herd: a new bio-inspired optimization algorithm," Communications in Nonlinear Science and Numerical Simulation, vol. 17, no. 12, pp. 4831-4845, 2012.

[20] G. Wang, L. Guo, H. Wang, H. Duan, L. Liu, and J. Li, "Incorporating mutation scheme into krill herd algorithm for global numerical optimization," Neural Computing and Applications, vol. 24, no. 3-4, pp. 853-871, 2014.

[21] G.-G. Wang, A. H. Gandomi, and A. H. Alavi, "Stud krill herd algorithm," Neurocomputing, vol. 128, pp. 363-370, 2014.

[22] G.-G. Wang, A. H. Gandomi, A. H. Alavi, and S. Deb, "A hybrid method based on krill herd and quantum-behaved particle swarm optimization," Neural Computing and Applications, vol. 27, no. 4, pp. 989-1006, 2016.

[23] A. L. A. Bolaji, M. A. Al-Betar, M. A. Awadallah, A. T. Khader, and L. M. Abualigah, "A comprehensive review: krill herd algorithm (KH) and its applications," Applied Soft Computing, vol. 49 , pp. 437-446, 2016. 